University of Wollongong

Research Online

Faculty of Social Sciences - Papers (Archive) Faculty of Arts, Social Sciences \& Humanities

2015

Transformation of traditional face-to-face teaching to mobile teaching and learning: Pedagogical perspectives

Jan Turbill

University of Wollongong, jturbill@uow.edu.au

Follow this and additional works at: https://ro.uow.edu.au/sspapers

Part of the Education Commons, and the Social and Behavioral Sciences Commons

Research Online is the open access institutional repository for the University of Wollongong. For further information contact the UOW Library: research-pubs@uow.edu.au 


\title{
Transformation of traditional face-to-face teaching to mobile teaching and learning: Pedagogical perspectives
}

\author{
Abstract \\ Teaching students in a face-to-face context has been and, in many institutions of education, still is the \\ only form of teaching in higher education. However, in the past 20 years, there has been a slowly \\ increasing movement toward transforming the higher education teaching and learning experience from \\ face-to-face to a mobile online learning experience. For most teachers this move is quite a challenge and \\ raises many issues and questions. These include questions such as: What mobile technologies are \\ available to employ? What teaching practices are best to use? Will student learning outcomes be better or \\ worse as a result? And for many the question asked is simply how can this be done? In this chapter a \\ framework for designing and implementing "online" pedagogy is shared. This framework is underpinned \\ by Turbill's (From a personal theory to a grounded theory in staff development. Unpublished doctoral \\ dissertation, University of Wollongong, Wollongong, 1994; The role of a facilitator in a professional \\ learning system: the frameworks project. In: Hoban G (ed) Teacher learning for educational change: a \\ systems thinking approach. Open University Press, Buckingham, pp 94-114, 2002) integrative theory of \\ learning and draws on Herrington and Bunker's (Quality teaching online: putting pedagogy first. In: Quality \\ conversations, proceedings of the 25th HERDSA annual conference, Perth, 7-10 July 2002, pp 305-312) \\ pedagogical guidelines. Both are unpacked and explained using a case study that provides the reader \\ with a pedagogical perspective that is both doable and proven to be successful.
}

\section{Keywords}

pedagogical, traditional, transformation, learning, mobile, teaching, perspectives, face

\section{Disciplines}

Education | Social and Behavioral Sciences

\section{Publication Details}

Turbill, J. (2015). Transformation of traditional face-to-face teaching to mobile teaching and learning: Pedagogical perspectives. In Y. Zhang (Eds.), Handbook of Mobile Teaching and Learning (pp. 221-233). Heidelberg, Germany: Springer. 


\title{
Transformation of Traditional Face-to-Face Teaching to Mobile Teaching and Learning: Pedagogical Perspective
}

\author{
Jan Turbill ${ }^{1}$
}

University of Wollongong, Building 40, 2500 Wollongong, NSW, Australia

\section{Jan Turbill}

Email: juturbill@uow.edu.au

\section{Abstract}

Teaching students in a face-to-face context has been and, in many institutions of education, still is the only form of teaching in higher education. However, in the past 20 years, there has been a slowly increasing movement toward transforming the higher education teaching and learning experience from face-to-face to a mobile online learning experience. For most teachers this move is quite a challenge and raises many issues and questions. These include questions such as: What mobile technologies are available to employ? What teaching practices are best to use? Will student learning outcomes be better or worse as a result? And for many the question asked is simply how can this be done? In this chapter a framework for designing and implementing "online" pedagogy is shared. This framework is underpinned by Turbill's (From a personal theory to a grounded theory in staff development. Unpublished doctoral dissertation, University of Wollongong, Wollongong, 1994; The role of a facilitator in a professional learning system: the frameworks project. In: Hoban G (ed) Teacher learning for educational change: a systems thinking approach. Open University Press, Buckingham, pp 94-114, 2002) integrative theory of learning and draws on Herrington and Bunker's (Quality teaching online: putting pedagogy first. In: Quality conversations, proceedings of the 25th HERDSA annual conference, Perth, 7-10 July 2002, pp 305-312) pedagogical guidelines. Both are unpacked and explained using a case study that provides the reader with a pedagogical perspective that is both doable and proven to be successful.

Keywords Face-to-face teaching - Online learning - Pedagogy - Learning theory - Community of learners

\section{Introduction}

In the past 20 years, there has been a slowly increasing movement toward transforming higher education teaching and learning experiences from traditional face-to-face to mobile online learning. For most teachers this move has been quite a challenge and raised many issues, concerns, and questions. These include questions such as: What mobile technologies are available to employ? What teaching practices are 
best to use? Will student learning outcomes be better or worse as a result? And for many the question asked is simply how can this be done? In this chapter a framework for designing and implementing "online" pedagogy is explored. This framework is underpinned by Turbill's ( $\underline{1994}, \underline{2002})$ integrative theory of learning and draws on Herrington and Bunker's ( 2002) pedagogical guidelines. Both are unpacked and explained using a case study that provides the reader with a pedagogical perspective that is both doable and proven to be successful.

\section{Background}

Most teachers enjoy their face-to-face teaching in higher education learning. It has been the "tried and true" way of teaching for many decades, and they feel comfortable and confident in this "way" of teaching. Usually the face-to-face approach for large cohorts of students comprises 1-2 h of lectures followed by $1 \mathrm{~h}$ smaller tutorial classes. In some cases when the cohort of students is smaller, it is possible to run 2-3 h face-to-face classes. Teaching Reading was such a class. The class of usually 10-15 students was developed and designed by a senior academic (who for the purpose of this chapter will be named Dr. Brock) and aimed to explore the range of theories and practices involved in the teaching of reading at the postgraduate level. The student cohort of mostly practicing teachers came together for $3 \mathrm{~h}$ "same time, same place" each week for 13 weeks (Redmond 2011). The class had been rated highly by the students for 5 years in each semester of the academic year.

The predictable flow of the $3 \mathrm{~h}$ involved:

- Discussion of set weekly readings and tasks in groups of three

- New input provided in the form of "mini" lecture by the teacher

- Collaborative small group workshops aimed to discuss and apply new input

- A whole group sharing and "pulling together" of ideas, outcomes, and challenges

- Review of homework for the following week, clarification of assessments (when needed), and any other issues

Critical to the effectiveness of the class was the assessment practices/tasks that were designed to be accumulative over the 13 weeks. Each week students were required to read and review a set article (between-session readings [BSR]) and to trial and review a given teaching practice (between-session tasks [BST]). They were asked to provide a one-page summary for each, identifying connections to their current and future professional practice. Students used their reflective one pager during the weekly sharing and discussion that always began our class. They submitted their weekly responses for marking every few weeks, and the marks are accumulated into final grades for assessments 1 and 2, respectively. The final assessment required students to review all their responses for the two assignments, reread where needed, and write an evidence-based rationale and teaching plan on the topic "Effective Teaching of Reading in My Context." Overall students and teacher rated the subject as very effective for their learning and for the 
changes in reading pedagogy that followed.

Students learned a lot from each other as well as from the teacher. They were able to discuss current issues as they arose and keep each other up to date with new reading research and practices. The teacher was able to introduce points of interest from the media and newly published articles as they occurred. As the weeks passed students became a "community of learners" (Barth 1990), sharing personal experiences of family and homelife as well as teaching and learning experiences from their respective classrooms. In any one class there was a range of teaching contexts and experiences. For example, in one class there were three teachers of many years of experience who had taught children from Grade 1 through to Grade 6, two high school teachers both with a science background, two specialist teachers of English, one teacher in his third year of teaching Grade 1, a teacher in the local prison, and another who taught vocational education (plumbing). Such a range of experiences led to rich discussions and many stories.

Therefore when this small but successful face-to-face graduate class was forced to "go online" using mobile technologies, it created a great deal of anxiety and uncertainty for Dr. Brock. There were two key reasons provided for this decision. Firstly, Dr. Brock was informed that the faculty could no longer sustain small classes of 10 or so students, and secondly, it was hoped that the online format would attract both national and international graduate students who were prepared to enroll in asynchronous classes. In particular a small private university in Minnesota, USA, had shown keen interest in offering an online version of this course in their newly developed doctoral program. And so the challenge began for this teacher. Just how does one transform a 13-week effective 3-h face-to-face class into an online format without losing teaching and learning opportunities such as interaction, reflection, sharing, and most importantly collaboration? How does one create the community of learners that was so evident in the face-to-face approach?

At the time there was little published research to guide such a move, nor were there sophisticated learning platforms available today. However, Dr. Brock had just completed her doctoral studies into what constituted effective professional development for teachers. The study developed a grounded theory of pedagogy that led to active and deep professional learning. Dr. Brock believed that this theory could be used as a framework to both guide and support the transformation of her face-to-face class to an online space.

In what follows is a clear explanation of this grounded theory and how it "works." Moreover the principles of this theory are used to demonstrate how Dr. Brock transformed her face-to-face synchronous class to an effective online asynchronous learning experience. Current research is juxtaposed throughout the explanation in order to respond to the many issues raised throughout this transformation. Finally key principles are highlighted in order to provide a sound pedagogical perspective for developing online and mobile learning.

\section{A Framework for Designing and Implementing "Online"}




\section{Pedagogy}

The model described in Fig. 1 is a visual representation of "an integrative theory of learning" (Turbill 1994, 2002). The theory emerged from research that investigated the "why" and "how" of a highly successful professional learning program for teachers. It can be used as a guide and frame for developing any teaching and learning enterprises. It aligns readily with action learning (Aubusson et al.2009; Albers $\underline{2008}$ ) and transformative pedagogy (Meyers 2008) and is underpinned by the principles of social constructivism (Twomey Fosnot $\underline{1996}$ ).

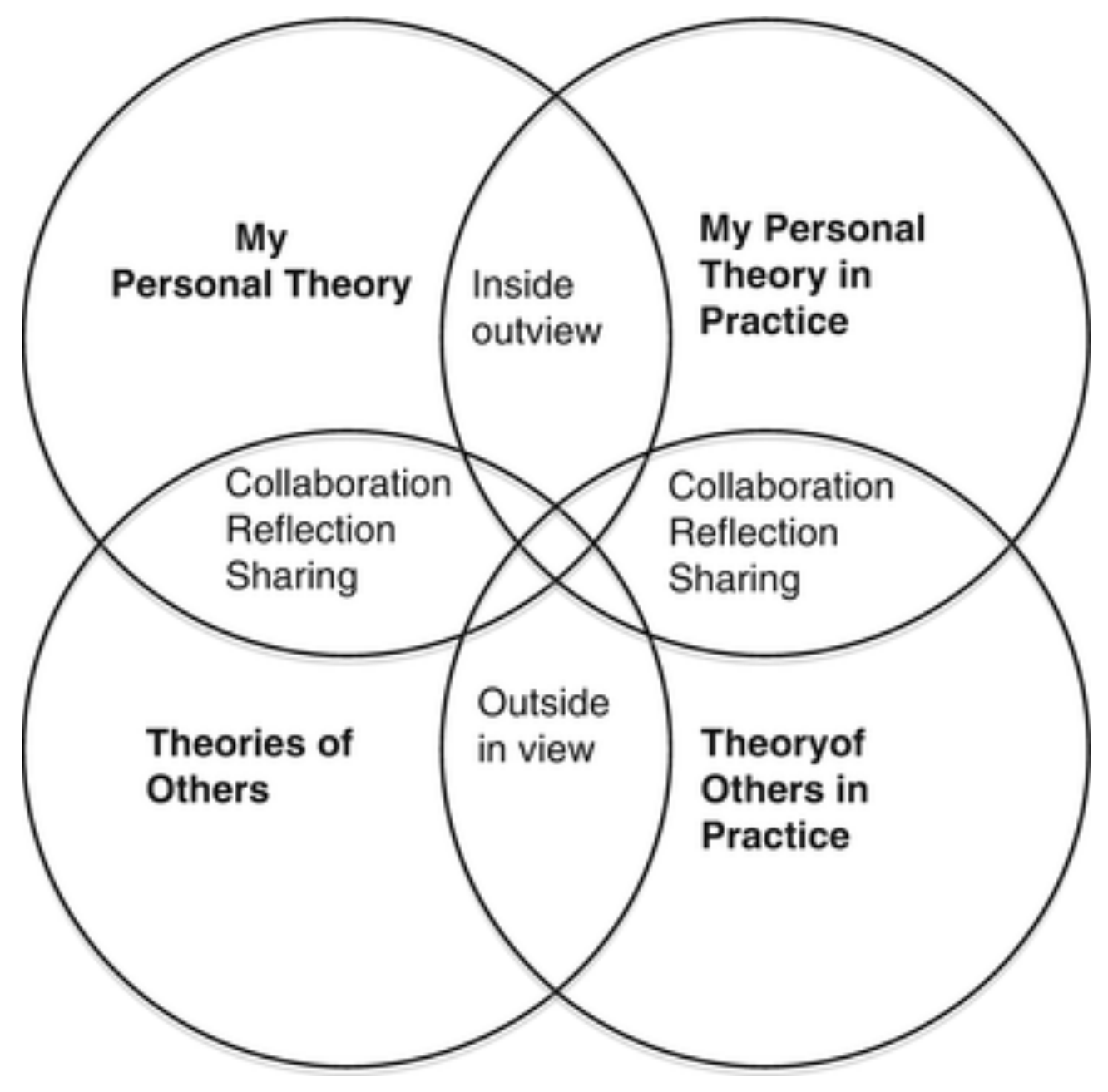

Fig. 1

An integrated theory of learning (Turbill $\underline{1994}, \underline{2002}$ )

Briefly, the model depicted in Fig. 1 demonstrates that there are personal (inside-out view) and external ( outside in view) dimensions of learning that need to be considered in any learning enterprise. All learners (students) bring some background knowledge, beliefs, and/or views about that which they are about to learn ( My Personal Theory) that underpin their existing knowledge, attitudes, and actions ( My Theory in Practice). This inside-out view is constantly being challenged and informed (or should be) by new information, ideas and input (The Theories of Others), and new actions and practices ( Theories of Others in Practice). Both dimensions are important and need to be valued equally. Critical in the construction of "new learning or knowledge" is the integration between "my inside view" and "the outside view" of that which is to be learned. Key drivers of such integration are the interactive processes that occur through reflection, sharing, and collaboration.

The model dictates therefore that certain structures and processes should be put in place for such 
interaction and integration to occur. This, in turn, leads to deep learning and understandings that becomes My Personal Theory. Langer ( $\underline{1998}$ ) refers to such learning as moving toward "mindful learning" in that the knowledge and understandings are said to be "known"; however, the knower is conscious that such knowing will be constantly challenged and changing.

For such a state of knowing to occur, the structures (e.g., teaching practices, assessments) and processes need to be carefully aligned and indeed synergistic in their operation. Thus the challenge for the teacher, the designer, the developer, or facilitator of that which is to be "learned" becomes choosing the "right" mix of structures and their respective processes so that optimal learning conditions not only exist but are made operational in such a way that they will become synergistic (Turbill 1994, 2002).

With the skillful and judicious selection of structures (teaching practices and assessment tasks), a learning culture is created in which there are sufficient learning processes in place to engage and enable deep learning. These include:

- Time for reflection, both written and spoken

- Time for sharing experiences and responses to readings with peers

- Opportunities for collaborative learning in small groups

- Opportunities to try and/or apply new practices

- Input (new knowledge) through a variety of media

- Readings that support, extend, and challenge the various concepts introduced in the course - Opportunities to work collaboratively (Turbill 2001)

No one structure is sufficient, and none is more important than another, but together they operate synergistically so that any potential inhibiting factor in the learning culture will have only a temporary lifespan as learners work through what they want or need to know and learn. In such learning cultures, trusting and caring relationships develop. Learners become highly supportive of one another's efforts and understandings. A shared meaning begins to develop among the learners and with it a shared language. This does not mean that everyone has the same views, beliefs, or depth of knowledge - far from it - but it does mean that members of the learning culture begin to understand one another's perspectives. The learning culture moves toward what Barth $(\underline{1990})$ calls a "community of learners." Such a community develops a sense of belonging that Lave and Wenger ( $\underline{1991})$ argue is an intrinsic condition for the creation and sharing of knowledge.

\section{Principles for Designing and Implementing Online Courses}

Having made the decision to go "online," Dr. Brock found there were many more decisions ahead. Before trying to adapt the teaching and learning activities (the structures) she had used successfully in her faceto-face teaching space, it was found she needed to learn just what technologies were available to her and her students in an online learning space, a learning space where students would no longer participate in 
the "same time, same place" approach. In particular, it was necessary to learn what mobile technologies her institution supported and just how to go about seeking support in knowing what affordances these offered to best enhance her teaching and engage her learners.

Redmond ( 2011, p. 1051) explains, "The changing nature of both the student body and available technologies have required academics to change their approaches." She offers four categories of teaching and learning spaces, namely:

1. Same time, same place - participants operate in the more traditional face-to-face teaching approach.

2. Different time, same place - participants interact in the same space with all participants, but at a time they choose, for example, asynchronous online discussions.

3. Same time, difference place - participants work independently but, at the same time, use online social media tools such as Skype and videoconferencing.

4. Different time, different place - participants are separated geographically and by time and operate always in asynchronous mode.

The choice of teaching and learning space is contingent upon the range and availability of technology tools and the affordances these offer. Redesigning a face-to-face traditional course using an integrative pedagogical approach underpinned by constructivism also requires changes in roles and responsibilities of teacher and students, use of technology, relationships, and sometimes a perceived change of prestige and power (Redmond 2011).

There are many successful structures that Dr. Brock had used in face-to-face teaching. But which of these would transfer successfully to an online learning space was an unknown in the first instance. Herrington and Bunker's ( 2002 , p. 307) pedagogical guidelines help to address this decision. Their guidelines take into account the affordances offered by the mobile technologies and "assist both academics and instructional designers as they design new online units." Moreover the guidelines can be used as an evaluative tool "to assess the quality of existing online units determining areas of possible improvement." These guidelines serve as a useful framework to keep in mind as one moves to the actual designing of the online course.

\section{Building an Online Course}

The first step in developing an online course should be to scope out a "big picture" of all the "structures" needed in the course. Figure 2 is such a scoping of the big picture of the online course for the graduate class Teaching Reading that Dr. Brock developed. The process of scoping the overview highlighted the many connections between and among the range of structures that had been so effectively part of the faceto-face class and that were highly desirable to be part of an online class. Working through this process also highlighted the areas where there was going to be the need for technology designer support. 


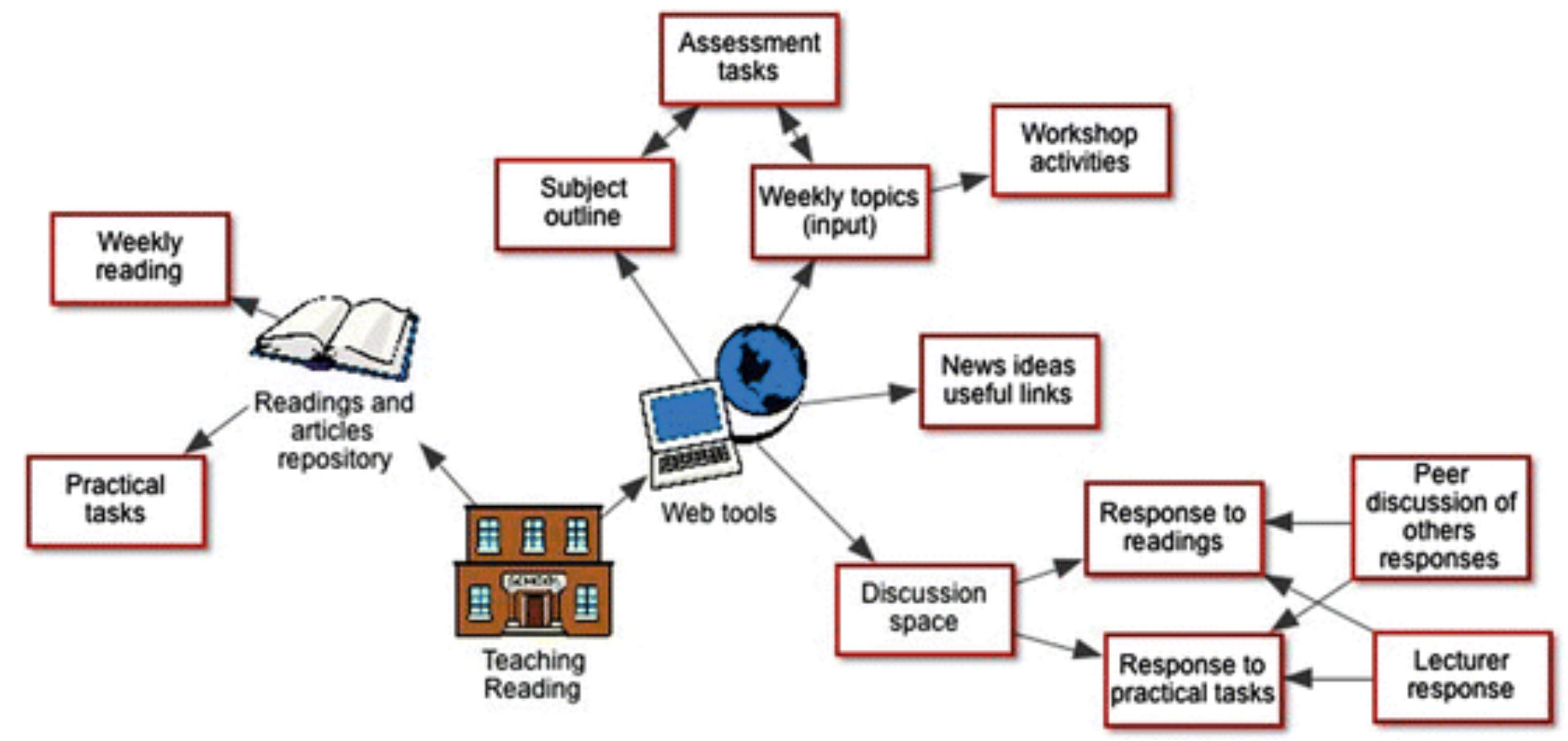

\section{Fig. 2}

Structures in teaching reading course

Having scoped out the design of the course as a whole, it became apparent that the weekly topics, activities, workshops, and readings for the whole course need to be prepared and "ready to go" before the course began. The teaching space, "different time - different place" (Redmond 2011), required that the logic and flow of the key concepts, workshop tasks, and understandings needed to be clearly written and highly explicit so students could move through the topics with as little confusion as possible. Keeping the guidelines in Table 1 clearly in mind supported Dr. Brock's desire to develop an engaging learner-centered environment with many opportunities for collaboration and real-life tasks and problems in the teaching of reading.

\section{Table 1}

Pedagogical guidelines (Herrington and Bunker 2002)

Description

The learning activities involve tasks

Authentic tasks that reflect the way in which the

knowledge will be used in real-life settings

Examples

- Problem-based learning activities using real-life contexts

- Learning tasks based in workplace settings

- Tasks are complex and sustained

- Tasks are set that require students to collaborate meaningfully

Students collaborate to create products that could not be produced individually
- Peer evaluation, industry mentors 
tasks. Students were asked to write their responses online and posted them for all to read (pink outline indicates students' submitted responses).

Making Connections provided a summary of the key connections that were deemed important in that topic. Students were asked to add further connections, particularly any pertaining to their workplace. For the Next Topic listed Between Topic Reading(s) (BTRs) and Between Topic Activities (BTAs) that students were required to carry out and respond to between topics. The former were set readings that students were asked to respond to using two key questions as a framework:

- What are the key points for me in this article?

- What are the implications of these points for my teaching of reading in my particular context?

The students' responses were to be composed in "academic" writing, using appropriate citations and referencing, and posted to the online discussion forum found in Student Responses. Where relevant, students were to cite their classmates' comments, as these were perceived as published pieces and thus constituted the "theories of others." Students were also encouraged to make connections between their set readings and the practical activities. These responses in turn accumulated, as in the face-to-face class, into two of the three assessment tasks.

\section{Running the Course}

The first online cohort began with nine students and had mixed results. Both students and teacher found it "a lot of work." All argued that the workload had to be reduced. The discussion space was the typical threaded forum and it became unwieldy and confusing. Students complained that often they could not find their peers' responses, and if they did, there was no time to read them, let alone make any personal comments. The discussion space, it was decided, had to be reviewed and changed. An even more disturbing outcome was that students commented that they tended to feel isolated and did not feel they "knew" their fellow classmates. They certainly did not feel part of an "engaging learning community." Thus while the assessment tasks were deemed to be authentic and meaningful as Herrington and Bunker ( 2002) suggest, the opportunities to collaborate with peers and to feel part of an engaging learning environment were wanting. It was deemed therefore necessary to explore new ways of interacting and sharing with each other within the online space.

Thus several "structures" had to be changed. First, it was decided that in the Workshop Tasks students would still be required to post their responses to the activities, but they would be no longer required to respond to each other's posts, although they were encouraged to read each other's postings. Second, in Making Connections, it was decided that no response would be required at all. This decision was based on the students' comments that any response they may have posted in Making Connections will mostly likely be repeated in their final response. Third, in Students' Responses a more organized threaded forum was designed for students to post their structured responses to set readings (BTRs) and activities (BTAs). And 
finally students were no longer required to respond to each other's postings in this space, unless they wanted to do so.

In order to set up a more informal mode of interaction, an e-mail Listserv was introduced to which students subscribed in the first week of the course. Because e-mail was perceived as more informal, it was hoped students would be more prepared to "talk" to the teacher and one another as they might do in a face-to-face setting. It was in this space where interaction, sharing, reflection, and collaboration could take place, it was hoped, albeit in an asynchronous space.

To ensure that students began to "know" each other, they were asked to post personal background information in their first week's post and where relevant throughout the course. They were also invited to upload a photo of themselves. Dr. Brock modeled this in the first weeks by sharing information about her weekend, her anticipation in meeting new students online, and, as in later posts, stories about her dog, important events, and so on. Students followed suit and shared their teaching contexts, school happenings, stories about their own children and those they taught, and more. Such "chatter" served an important role in allowing all to "know" each member on the Listserv and thus build a "community of learners ." In many cases students who found they lived near each other organized to meet offline over coffee and chat about their work. Those who lived overseas or interstate also developed online friendships by e-mailing and even Skyping each other outside of the class space.

While students' responses to the readings (BTRs) and activities (BTAs) were posted on the designated forum, they were also encouraged to use the Listserv to share key connections, ideas, and questions. This led to some very interesting discussions and debates.

As the facilitator (and if needed moderator) of the Listserv, it was important for Dr. Brock to post (and thus model) relevant news items, web links to YouTube, useful sites, and probing questions and generally to encourage interaction. (It is important to note that social media has now many different mobile technologies that could have been used other than Listserv, and there will be many chapters in this handbook that will provide information about these tools.)

A critical "structure" change was that of the teacher's role. Too often Dr. Brock found that responses to students' questions and comments turned into "mini lectures." This practice tended to deter students from providing comments and input. The literature strongly suggests that it is important that the lecturer not be perceived as the expert (Burton 1998; Pelz 2004). The course had many "experts" in those who had written the book chapters and journal articles that made up the assigned readings, as well as articles, news items, and so on, that students posted. A teacher's role should be to participate in, mediate, and facilitate student learning in a safe and inviting environment (Meyers $\underline{2008}$ ). Taking on a more facilitating role rather than an expert role is not easy for teachers. However, many have argued that it is most important that the teacher needs to be the "guide on the side" rather than the "sage on the stage."

\section{Future Directions}


Over the ensuring years, these structures and processes have "worked" in each session's course to build a strong community of learners who are highly engaged, who are willing to share and challenge each other, and who develop deep knowledge and analytic skills about the teaching of reading (Meyers 2008). While the online space allows for a general "repository" for the input, tasks, and students' responses, the use of interactive mobile tools is critical in bringing together the personal dimension (inside-out view) and external dimensions (outside in view), as outlined in Fig. 1 , in order that there are many opportunities to reflect, collaborate, and share. Students who come from various educational backgrounds and geographical locations become online professional colleagues and friends. A foundation of trust develops where students become self-directed and empowered learners. Meyers ( $\underline{2008}$, p. 220) suggests that online discussions allow students to "express themselves thoughtfully without interruption, which is particularly significant for those at a greater risk for marginalization in [face-to-face] class due to their gender, race, social class or even personality style."

Figure 4 demonstrates an analysis of the nature of interactions that occurred on the Listserv (or need to occur using any social online medium). Each of these four key interactive structures management and organization, personal contextualizing, professional contextualizing, and knowledge building plays a critical and synergistic role in building that foundation of trust that in turn leads to highly effective learning communities.

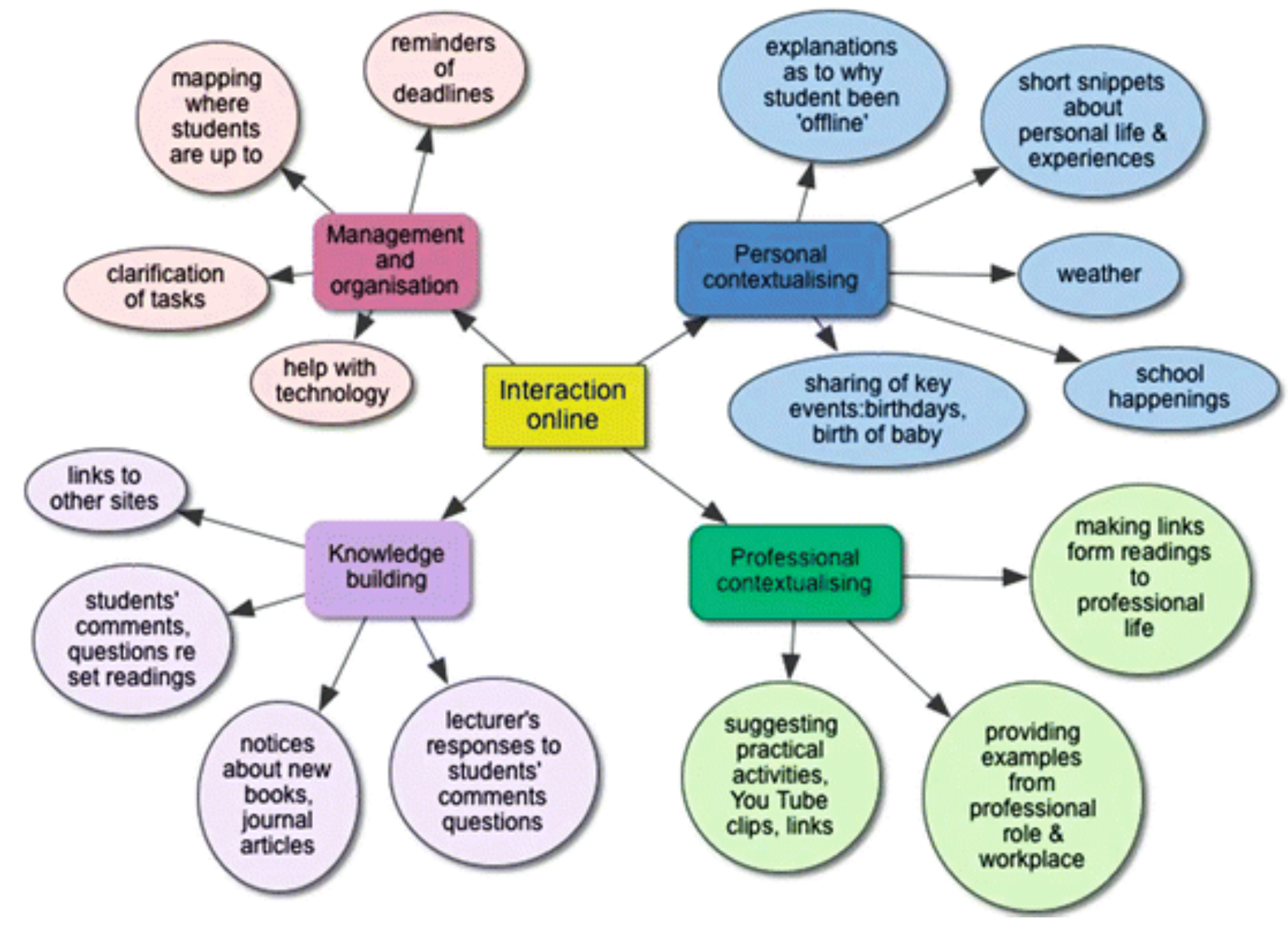

Fig. 4

Structures involved in effective online interaction 
principles to be learned and used in order to design and develop effective mobile teaching and learning. These include:

- Tasks need to be clearly described, with the purpose of each made very clear.

- Assessment tasks need to be clearly described and serve as learning experiences in themselves.

- Communication tools need to be chosen to provide students with opportunities "to get to know" and trust each other in order to become a member of a learning community.

- The teacher needs to be a participant in and facilitator of students' learning.

- The teacher needs to "listen" to students and be prepared to be flexible according to their needs.

The pedagogical perspective explored in this chapter can be neatly summarized by Pelz's ( $\underline{2004})$ principles of effective online pedagogy:

- Let the students do (most of) the work.

- Interactivity is heart and soul of effective asynchronous learning.

- Strive for presence.

\section{Cross-References}

Characteristics of Mobile Teaching and Learning

Mobilizing PD: Professional Development for Sessional Teachers Through Mobile Technologies

\section{References}

Albers, Cheryl. 2008. Improving pedagogy through action learning and scholarship of teaching and learning. Teaching Sociology 36(1):79-86.

\section{$\underline{\text { CrossRef }[\pi}$}

Aubusson, Peter, Robyn Ewing, and Garry Hoban. 2009. Action learning in schools: Reframing teachers' professional learning and development. London/New York: Routledge.

Barth, Roland. 1990. Improving schools from within. San Francisco: Jossey-Bass.

Burton, Wendy. 1998. Facilitating online learning: Charting the conversation . Paper presented at the third annual teaching in the Community Colleges conference, online instruction: trends \& issues II, Honolulu. http://tcc.kcc.hawaii.edu/previous/TCC\%201998/paper/burton.html. Accessed Jan 2011.

Herrington, Anthony and Bunker, Alison. 2002. Quality teaching online: Putting pedagogy first. In Quality conversations, proceedings of the 25th HERDSA annual conference, Perth, Western Australia, 7- 
10 July 2002, 305-312 . http://www.herdsa.org.au/wp-content/uploads/conference/2002/papers/ HerringtonA.pdf. Accessed 20 July 2014.

Langer, Ellen. 1998. The power of mindfulness learning. Reading: De Capo Press.

Lave, Jean and Etienne Wenger. 1991. Situated learning: Legitimate peripheral participation. New Jersey, USA:Cambridge University Press.

Meyers, Steven A. 2008. Using transformative pedagogy when teaching online. College Teaching (Fall):219-224. http://sites.roosevelt.edu/smeyers/files/2011/04/transformative.pdf. Accessed 20 July 2014.

Pelz, Bill. 2004. (My) Three principles of effective online pedagogy. Journal of Asynchronous Learning Networks 8(3):33-46. https://www.ccri.edu/distancefaculty/pdfs/Online-Pedagogy-Pelz.pdf. Accessed 20 July 2014.

Redmond, Petrea. 2011. From face-to-face teaching to online teaching: pedagogical transitions . In ASCILITE 2011: 28th annual conference of the Australasian Society for computers in learning in tertiary education: Changing demands, changing directions, 4-7 Dec 2011, Hobart. http://eprints.usq.edu.au/ 20400/. Accessed 20 July 2014.

Turbill, Jan. 1994. From a personal theory to a grounded theory in staff development. Unpublished doctoral dissertation, University of Wollongong, Wollongong.

Turbill, Jan. 2001. A face-to-face graduate class goes online: Challenges and successes. Reading Online 5(1). http://www.readingonline.org/international/inter_index.asp?HREF=turbill1/index.html. Accessed 20 July 2014.

Turbill, Jan. 2002. The role of a facilitator in a professional learning system: The Frameworks project. In Teacher learning for educational change: A systems thinking approach, ed. Garry Hoban, 94-114. Buckingham: Open University Press.

Twomey Fosnot, Catherine (ed.). 1996. Constructivism: Theory, perspectives, and practice. New York: Teachers College Press. 